\title{
Histological, transcriptomic and in vitro analysis reveal an intrinsic activated state of myogenic precursors in hyperplasic muscle of trout
}

Sabrina Jagot, Nathalie Sabin, Aurélie Le Cam, Jérôme Bugeon, Pierre-Yves Rescan and Jean-Charles Gabillard

\begin{abstract}
Background: The dramatic increase in myotomal muscle mass in post-hatching fish is related to their ability to lastingly produce new muscle fibres, a process termed hyperplasia. The molecular and cellular mechanisms underlying fish muscle hyperplasia largely remain unknown. In this study, we aimed to characterize intrinsic properties of myogenic cells originating from hyperplasic fish muscle. For this purpose, we compared in situ proliferation, in vitro cell behavior and transcriptomic profile of myogenic precursors originating from hyperplasic muscle of juvenile trout (JT) and from non-hyperplasic muscle of fasted juvenile trout (FJT) and adult trout (AT).
\end{abstract}

Results: For the first time, we showed that myogenic precursors proliferate in hyperplasic muscle from JT as shown by in vivo BrdU labeling. This proliferative rate was very low in AT and FJT muscle. Transcriptiomic analysis revealed that myogenic cells from FJT and AT displayed close expression profiles with only 64 differentially expressed genes (BH corrected p-val < 0.001). In contrast, 2623 differentially expressed genes were found between myogenic cells from JT and from both FJT and AT. Functional categories related to translation, mitochondrial activity, cell cycle, and myogenic differentiation were inferred from genes up regulated in JT compared to AT and FJT myogenic cells. Conversely, Notch signaling pathway, that signs cell quiescence, was inferred from genes down regulated in JT compared to FJT and AT. In line with our transcriptomic data, in vitro JT myogenic precursors displayed higher proliferation and differentiation capacities than FJT and AT myogenic precursors.

Conclusions: The transcriptomic analysis and examination of cell behavior converge to support the view that myogenic cells extracted from hyperplastic muscle of juvenile trout are intrinsically more potent to form myofibres than myogenic cells extracted from non-hyperplasic muscle. The generation of gene expression profiles in myogenic cell extracted from muscle of juvenile trout may yield insights into the molecular and cellular mechanisms controlling hyperplasia and provides a useful list of potential molecular markers of hyperplasia.

Keywords: Fish, Myoblast, Proliferation, Differentiation, Hyperplasia, Muscle stem cell

\section{Background}

Many fish teleosts have the extraordinary ability to growth throughout their life, and to continuously produce new muscle fibres (hyperplasia). The persistence of hyperplasic growth after juvenile stage was reported in large final size fish such as gilthead bream [1], carp [2], european sea bass [3] and rainbow trout $[4,5]$ and was found in a lesser extent in the small sized zebrafish [6].

\footnotetext{
* Correspondence: Jean-Charles.gabillard@inra.fr

INRA, LPGP, Fish Physiology and Genomic Laboratory, 35000 Rennes, France
}

Nevertheless, production of new muscle fibres in fish myotome decreases with age and eventually stops [7]. Such as muscle fibre input dynamics was notably observed in trout $[4,5]$. Furthermore, it is well known that fasting stops growth [8] and an inhibition of in vitro proliferation of myogenic precursors in fasted rainbow trout has been observed [9].

Muscle hyperplasia requires muscle stem cells, also called satellite cells [10] which are localized between

(c) The Author(s). 2018 Open Access This article is distributed under the terms of the Creative Commons Attribution 4.0 International License (http://creativecommons.org/licenses/by/4.0/), which permits unrestricted use, distribution, and 
myofibre and basal lamina. Once activated during development, growth or after muscle injury, myogenic precursors proliferate and differentiate to eventually form nascent myofibres [11, 12]. Myogenic differentiation is associated with the expression of the myogenic regulatory factor MyoD [13]. Then, the expression of myogenin at the onset of the satellite cell differentiation triggers the expression of fusogenic and structural protein such as myomaker and myosin heavy chain [14, 15]. Satellite cells have been clearly identified in situ in muscle of carp [16] and zebrafish [17]. In vitro, myogenic precursors extracted from salmon, trout, sea bream, zebrafish, pacu, turbot and carp muscle proliferate and fuse into myotube $[6,9,18-23]$. Whether myogenic progenitors in fish hyperplasic muscle exhibit specific intrinsic physiological state predisposing them to produce new myofibres is unknown. To test this hypothesis, and investigate the biological processes involved, we extracted these cells from hyperplasic muscle of juveniles growing trout (JT), and non-hyperplasic muscle of fasted juvenile trout (FJT) and adult trout (AT), and compared their ability to proliferate in situ, as well as their transcriptome and their proliferation and differentiation capacities in culture.
The use of two non-hyperplasic muscle conditions allowed us to discard differentially expressed genes related to nutritional status, age, etc., and thus to focus on differentially expressed genes specific to non-hyperplasic muscle. Our results converge to support the view that myogenic cells extracted from hyperplasic muscle of juvenile trout are intrinsically more potent than myogenic cells extracted from non-hyperplasic muscle.

\section{Results \\ Myogenic precursors proliferate in hyperplasic muscle during post-larval growth}

In order to quantify the number of proliferative satellite cells in trout of $2 \mathrm{~g}, 500 \mathrm{~g}$ and fasted trout of $5 \mathrm{~g}$, we developed immunofluorescence analysis to locate proliferative nuclei in satellite cell position, i.e. located under the basal lamina. For this purpose, we injected fish with BrdU and performed immunofluorescence analysis with an antibody against BrdU and laminin a major component of basal lamina. As shown in Fig. 1, the percentage of BrdU positive nuclei in juvenile trout was $7.2 \%$, whereas this proportion dropped to $1.3 \%$ in larger trout $(500 \mathrm{~g})$ and $0.1 \%$ in 3 -week fasted juvenile trout.

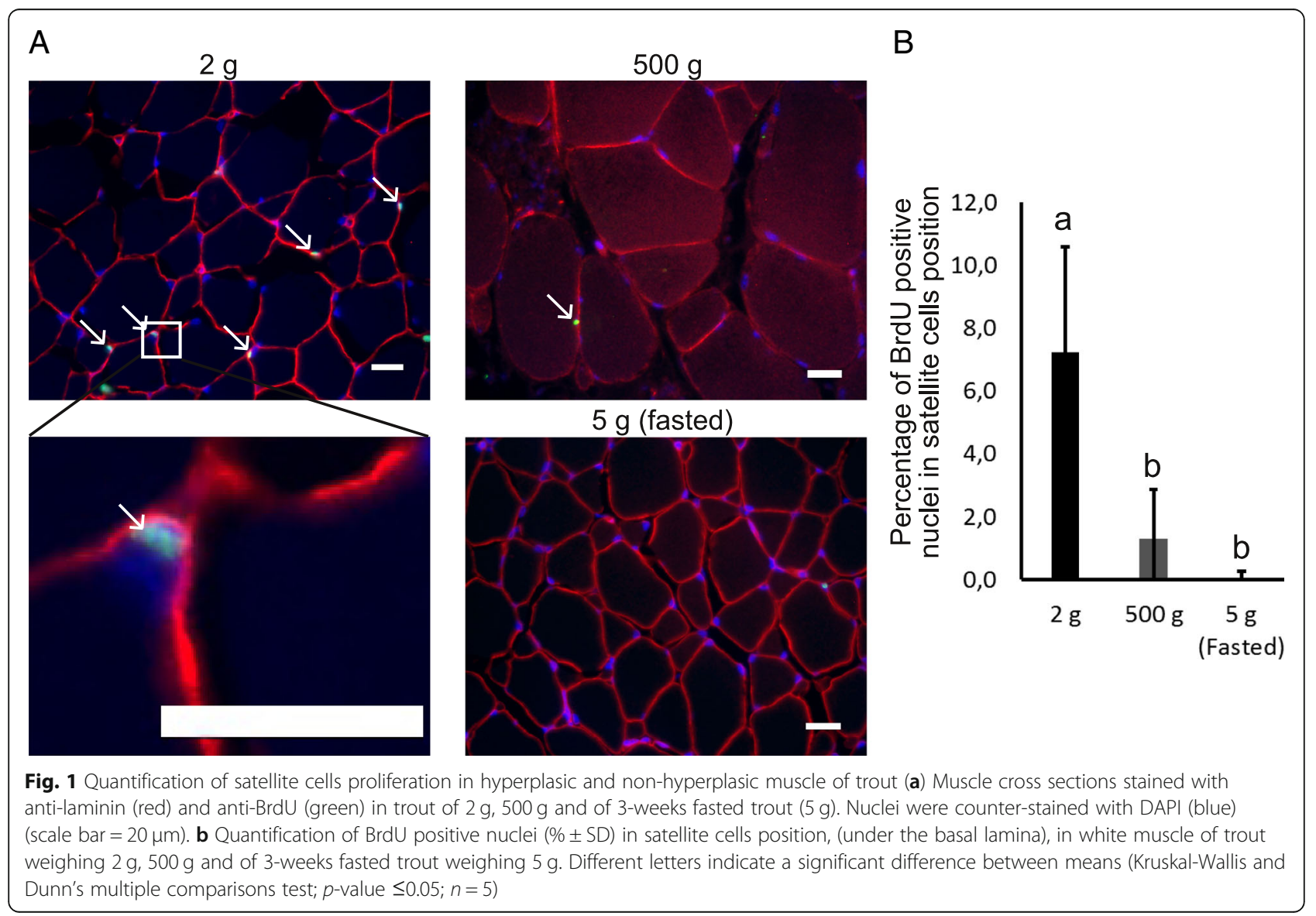


Myogenic precursors extracted from hyperplasic and nonhyperplasic trout muscles exhibit distinct transcriptome To better known the intrinsic molecular properties of myogenic precursors from hyperplasic muscle, we compared the transcriptome of myogenic precursors extracted from juvenile trout (JT) displaying hyperplasic muscle growth with that of myogenic precursors extracted from non-hyperplasic muscle resulting from fasted juvenile trout (FJT) and adult trout (AT). For this purpose, we first compared gene expression profiles between myogenic precursors from FJT and AT in order to identify genes whose differential expression would be specifically related to age or fasting. LIMMA statistical test [24] (BH corrected $\mathrm{p}$-val $<0.001$ ) showed that only 64 genes were differentially expressed between FJT and AT samples. These differentially expressed genes (DEGs) were subsequently discarded for further analysis. Using two LIMMA statistical tests $(\mathrm{BH}$ corrected $\mathrm{p}$-val $<0.001)$ a total of 3992 DEGs were identified between JT and FJT and 4253 DEGs between JT and AT. Then, we retained common genes found in this two differential analysis and found a total of 2623 differentially expressed genes between hyperplasic (JT) and non-hyperplasic muscle (FJT and AT). These differentially expressed genes were then hierarchically clustered. The unsupervised clustering, which is shown in Fig. 2, resulted in the formation of two major gene clusters. The cluster 1 comprised 1865 genes up regulated in JT myogenic precursors and cluster 2 comprised 758 genes down regulated in JT myogenic precursors.

\section{JT myogenic precursors exhibit transcriptomic signature of activated state cell}

DAVID analysis of the 1206 eligible genes from cluster 1 revealed significant enrichment (Table 1) in genes involved in translation $\left(p=2.8 \mathrm{E}^{-26}\right)$, mitochondrial activity $\left(p=3,85 \mathrm{E}^{-11}\right)$ and oxidative phosphorylation $(p=$ $\left.7,31 \mathrm{E}^{-12}\right)$. Among other significant functional categories inferred from up regulated genes in JT myogenic precursors, we found the GO term mitotic cell cycle ( $p=$ $2.26 \mathrm{E}^{-20}$ ). Genes belonging to this functional category included genes encoding cell division cycle (cdc) proteins (8), cyclin dependent kinases (6), cyclins (6), genes involved in chromosomes segregation (20) as shown in Fig. 3. Enrichment in genes involved in DNA metabolic process and replication such as minichromosome maintenance complex components, non-homologous end-joining factor1, DNA polymerases, DNA primases, DNA topoisomerases, replication proteins were also found. Cluster 1 also included many genes encoding epigenetic transcriptional regulators. Among them were Swi/Snf chromatin enzymes and several DNA (cytosine-5-)-methyltransferases. We found also many genes encoding extracellular components including collagens (14 genes), laminin subunits (3 genes) and entactin as well as genes contributing

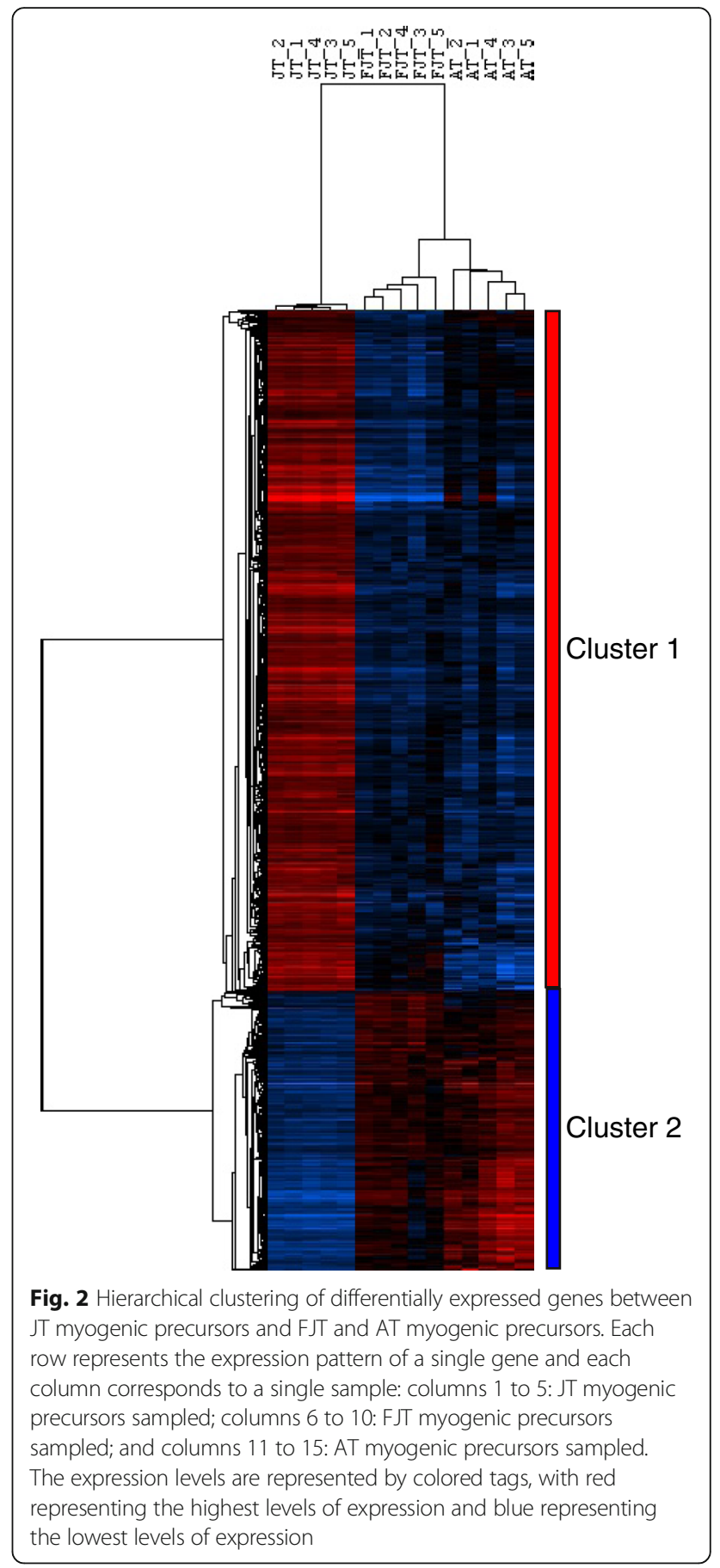

to the formation of the myofibrils (i.e, 8 genes encoding myosins, 5 genes encoding troponins, 2 genes encoding capping protein muscle $\mathrm{Z}$-line and 3 genes encoding tropomyosins). At last, besides the large number of myofibrillary proteins, we found many genes involved in myoblast differentiation and fusion such as six $1 b$, six $4 b$, mef2d, myogenin, tmem8c (myomaker), muscle creatine kinase, caveolin 3, Dock5 (Fig. 4). Overall, cluster 1 
Table 1 Functional categories inferred from up regulated genes in JT myogenic precursors

\begin{tabular}{|c|c|c|c|c|}
\hline & & Number of genes & $p$-value & $\begin{array}{l}\text { p.adj } \\
\text { (Benjamini) }\end{array}$ \\
\hline \multicolumn{5}{|c|}{ GO terms Biological Process } \\
\hline GO:0006412 & translation & 84 & $2,82 \mathrm{E}-26$ & 8.17E-23 \\
\hline GO:0006119 & oxidative phosphorylation & 30 & 7,31E-12 & $6.63 \mathrm{E}-9$ \\
\hline GO:0042775 & mitochondrial ATP synthesis coupled electron transport & 22 & $3,85 \mathrm{E}-11$ & $6.56 \mathrm{E}-9$ \\
\hline GO:0000278 & mitotic cell cycle & 80 & 2,26E-20 & $2.18 \mathrm{E}-17$ \\
\hline GO:0000280 & nuclear division & 51 & 2,38E-14 & $1.15 \mathrm{E}-11$ \\
\hline GO:0048285 & organelle fission & 52 & $3,10 \mathrm{E}-14$ & $1.28 \mathrm{E}-11$ \\
\hline GO:0007059 & chromosome segregation & 20 & $1,65 \mathrm{E}-06$ & $1.64 \mathrm{E}-4$ \\
\hline GO:0006260 & DNA replication & 30 & 3,83E-05 & $2.92 \mathrm{E}-3$ \\
\hline GO:0006259 & DNA metabolic process & 61 & 2,01E-05 & $1.67 \mathrm{E}-3$ \\
\hline \multicolumn{5}{|c|}{ GO terms Cellular Component } \\
\hline GO:0005840 & ribosome & 72 & $1,61 \mathrm{E}-29$ & $4.51 \mathrm{E}-27$ \\
\hline GO:0030529 & ribonucleoprotein complex & 102 & $1,59 \mathrm{E}-21$ & $1.49 \mathrm{E}-19$ \\
\hline GO:0005739 & mitochondrion & 211 & 1,77E-44 & $9.93 \mathrm{E}-42$ \\
\hline GO:0070469 & respiratory chain & 29 & $6,83 \mathrm{E}-14$ & $2.39 \mathrm{E}-12$ \\
\hline GO:0005839 & proteasome core complex & 10 & 3,84E-06 & $6.74 \mathrm{E}-5$ \\
\hline GO:0000776 & kinetochore & 16 & $3,10 \mathrm{E}-04$ & $4.04 \mathrm{E}-3$ \\
\hline GO:0030017 & sarcomere & 13 & 4,64E-02 & 0.31 \\
\hline
\end{tabular}

Table of the most significant Gene Ontology terms in Biological Process and Cellular Component that were found following functional enrichment analysis (DAVID Software 6.7) among genes up regulated in JT myogenic precursors

showed enrichment in genes involved in protein synthesis, cell division and myogenic differentiation.

\section{Genes associated with the quiescent state are down regulated in JT myogenic precursors}

Cluster 2 comprised genes that were down regulated in JT myogenic precursors compared to both FJT and AT myogenic precursors. In this cluster, we identified genes of the Notch pathway, suggesting a repression of quiescent state. Associated with this quiescency state pathway we found jagged $1 b$, jagged $2 b$, dll4, dlc, notch1a, notch1b, notchl, her6 and hey1 among genes contained in cluster 2. We detected some genes which play repression roles in proliferation as hexim1b [25], stat3 [26], and Dach1 also known to inhibit Six protein activity [27]. Among the down regulated genes in JT myogenic precursors, we distinguished genes which plays repression roles in myogenic differentiation as ddit3 [28], trim33 [29], bhlhe40 [30], tal1 [31]. Moreover, a marker of quiescent satellite cells [32], nestin was down regulation in JT myogenic precursors. We also observed a global repression of the TGF $\beta$ pathway in JT myogenic precursors. Indeed, 7 genes involved in TGF $\beta$ pathway were down regulated in JT myogenic precursors (tgfb2, tgfbr1, bmpr $2 b$, bmpr1bb, smad3b, smad6a and acvrrl1) whereas 5 inhibitors of TGF $\beta$ pathway were up regulated in JT myogenic precursors (Bmp7a, gremlin2, dcn, fstl1b and fsta).
Overall, cluster 2 showed enrichment in genes involved in inhibition of proliferation, repression of myogenic differentiation and maintenance of cellular quiescent state.

\section{JT myogenic precursors have an enhanced intrinsic capacity for in vitro proliferation}

To know more about the intrinsic molecular properties of myogenic precursors of hyperplasic muscle compared to myogenic precursors of non-hyperplasic muscle, we carried out a primary cell culture of myogenic progenitors extracted from JT, FJT and AT conditions. Cell proliferation assays using BrdU showed a higher proliferation rate of JT myogenic precursors (40.1\%) after two days of culture compared to FJT (0.8\%) and AT (10.3\%) myogenic precursors (Fig. 5). Then, to determine whether the transcriptomic activation signatures were related to a differential cell behavior regarding proliferating capacity, we also measured the proliferation rate of JT, FJT and AT myogenic cells at 5, 8 and 11 days after plating. In JT myogenic precursors the proliferation rate increased from D2 to reach a maximum rate at D5 with $61.4 \%$ of BrdU positive nuclei, then the proliferation rate decreased from D8 to $42.4 \%$ to D11 to $31.4 \%$. In sharp contrast, proliferation rate of FJT myogenic precursors remained low and tended to increase up to $12,9 \%$ at D8. For AT myogenic precursors, the proliferation rate increased at D5 to $48.3 \%$ to almost 


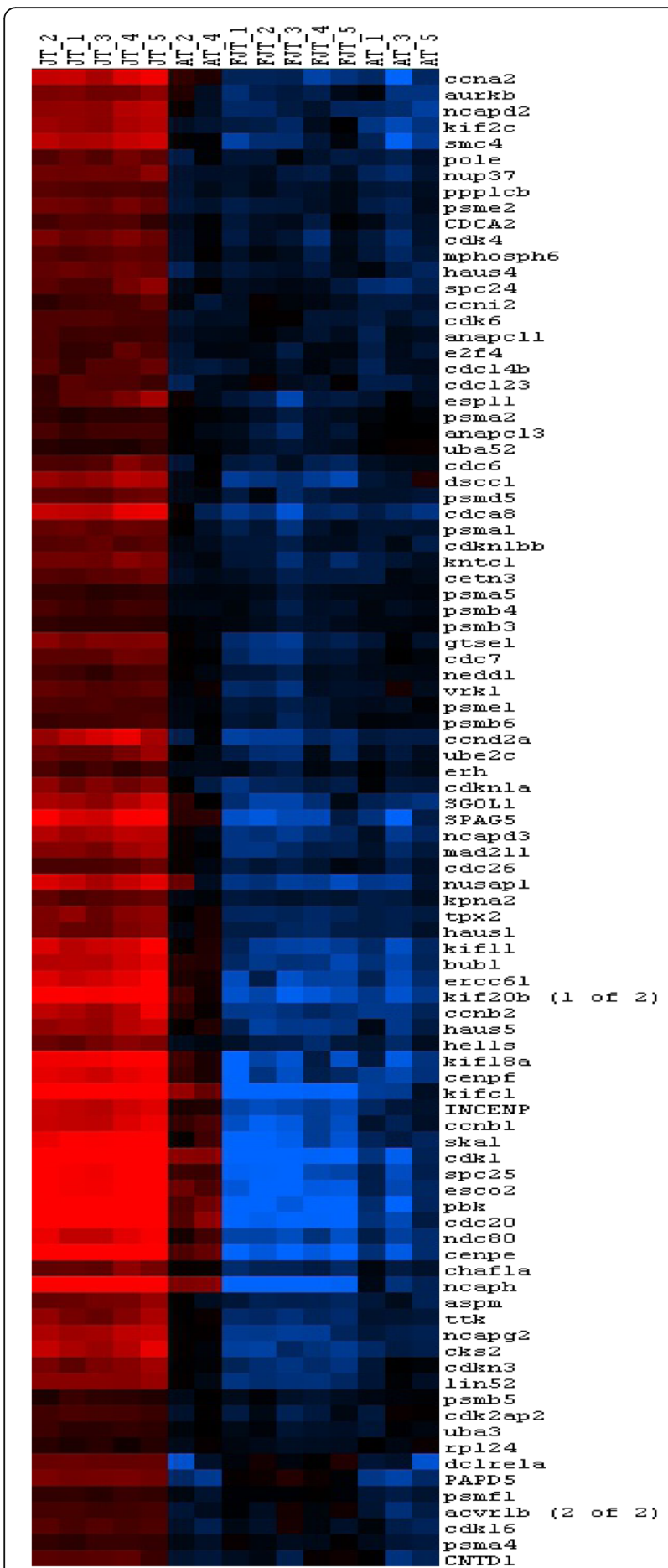

Fig. 3 Hierarchical clustering of differentially expressed cell cycle genes between JT myogenic precursors and FJT and AT myogenic precursors. Each row represents the expression pattern of a single gene and each column corresponds to a single sample: columns 1 to 5: JT myogenic precursors sampled; columns 6 to 10: FJT myogenic precursors sampled; and columns 11 to 15: AT myogenic precursors sampled. The expression levels are represented by colored tags, with red representing the highest levels of expression and blue representing the lowest levels of expression

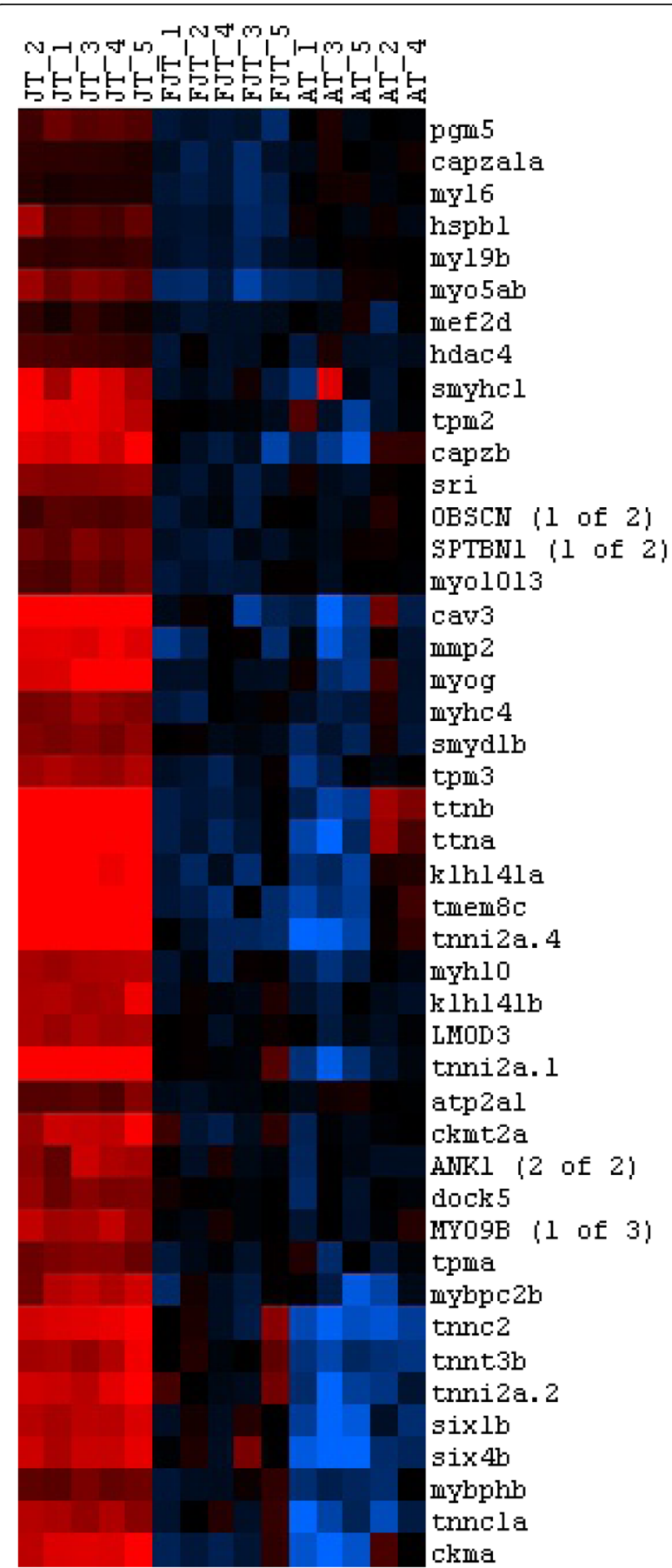

Fig. 4 Hierarchical clustering of differentially expressed myogenic genes between JT myogenic precursors and FJT and AT myogenic precursors. Each row represents the expression pattern of a single gene and each column corresponds to a single sample: columns 1 to 5: JT myogenic precursors sampled; columns 6 to 10: FJT myogenic precursors sampled; and columns 11 to 15: AT myogenic precursors sampled. The expression levels are represented by colored tags, with red representing the highest levels of expression and blue representing the lowest levels of expression 


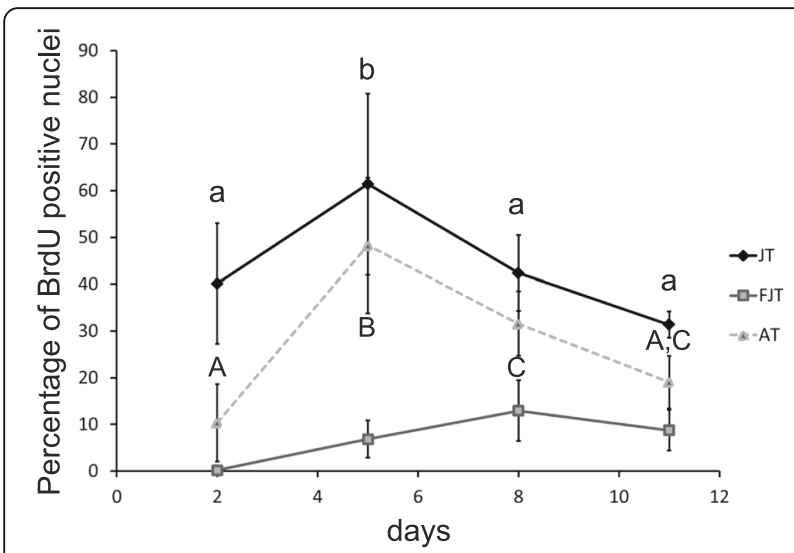

Fig. 5 Proliferation rate of JT, FJT and AT myogenic precursors after $2,5,8,11$ days of plating (D2, D5, D8 and D11). Each point represents the mean $(\% \pm S D)$ of BrdU positive nuclei ratio for each condition at D2, D5, D8 and D11. Different letters indicate a significant difference between means (two-way ANOVA and Tukey's multiple comparisons test; $p$-value $\leq 0.05 ; n \geq 5$ )

reach the proliferation rate in $\mathrm{JT}$ myogenic precursors and decreased from D8 to $31.6 \%$ and at D11 to $19.1 \%$. Thus, the kinetic of proliferation of the AT precursors was close to that one of JT but with a lower rate from D5 to D11. Overall, myogenic precursors of JT exhibit a global enhanced proliferation capacity under in vitro conditions compared to FJT and AT.

\section{JT myogenic precursors have an enhanced capacity for in vitro myogenic differentiation}

To go further on the characterization of the intrinsic molecular properties of myogenic precursors of hyperplastic muscle, we quantified the in vitro differentiation capacities of JT, FJT and AT myogenic precursors. At D2, we observed an extremely low differentiation rate in JT (1.4\%), FJT (1\%) and AT (1.6\%) myogenic precursors (Fig. 6). Because of the low differentiation at D2, this result indicates that very few differentiated muscle cells (myocytes) were seeded at the beginning of the cell culture. Then, we also measured the differentiation rate at 5,8 and 11 days after plating of JT, FJT and AT myogenic progenitors. In JT myogenic precursors the differentiation rate increased at D5 to $11.6 \%$, D8 to $24.4 \%$ and reach a maximum rate at D11 with $28 \%$ of nuclei contained in myosin positive cells. In sharp contrast, the differentiation of FJT precursors remained very low during the first 8 days $(<0.5 \%)$ then a differentiation resumption was observed at D11 (6.4\%). For AT myogenic precursors, no significant increase of the differentiation rate was observed even after 11 days of culture. Overall, JT myogenic precursors exhibited a global enhanced differentiation capacity under in vitro conditions.

Evaluation of the expression level by qPCR of myogenin and myomaker after 2 days in cell culture validated

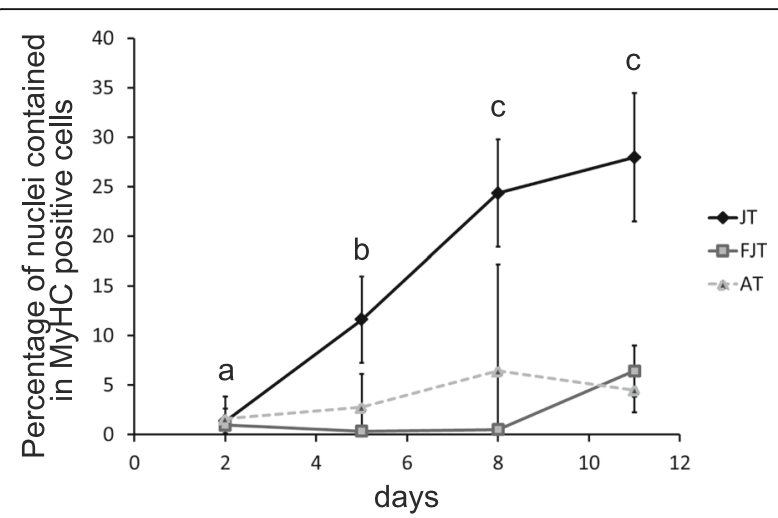

Fig. 6 Differentiation rate of JT, FJT and AT myogenic precursors after 2, 5, 8, 11 days in culture (D2, D5, D8 and D11). Each point represents the mean $(\% \pm S D)$ of the percentage of nuclei contained in MyHC positive cells for each condition at D2, D5, D8 and D11. Different letters indicate a significant difference between means (two-way ANOVA and Tukey's multiple comparisons test; $p$-value $\leq 0.05 ; n \geq 6)$

the transcriptomic results as shown in Fig. 7. Indeed, the expression of myogenin and myomaker were higher in JT myogenic precursors compared to AT and FJT myogenic precursors. In addition, the expression level of myogenin and myomaker after 8 days in culture increased in FJT myogenic precursors. These were contrasting with expression level in AT myogenic precursor that did not exhibit such an increase between D2 and D8. Overall, qPCR data validated our previous results with JT myogenic precursors as more engaged in differentiation program than AT and FJT myogenic precursors.

\section{Discussion}

Formation of new myofibres occurs lastingly in fish myotome. This process, termed hyperplasia, requires proliferation, differentiation and fusion of muscle stem cells (satellite cells) to form new multinucleated myofibres. We examined in this study the hypothesis that post-hatching muscle hyperplasia in fish is associated with an intrinsic physiological status of myogenic precursors predetermining them to self-renew and differentiate. For this purpose, we examined proliferation of trout satellite cells in vivo and compared gene expression profiling and in vitro myogenic potential of satellite cells extracted from juvenile trout muscle displaying intense hyperplastic growth (JT), with satellite cells extracted from trout muscle that no longer exhibited muscle hyperplasia, namely fasted juvenile trout (FJT) and adult trout (AT).

Many studies on mammalian isolated satellite cells were carried out on cells directly isolated from muscle and purified by FACS using fluorescent reporters or cell surface marker [33]. As these technologies cannot yet be used in trout fish, we took advantage of the specific 


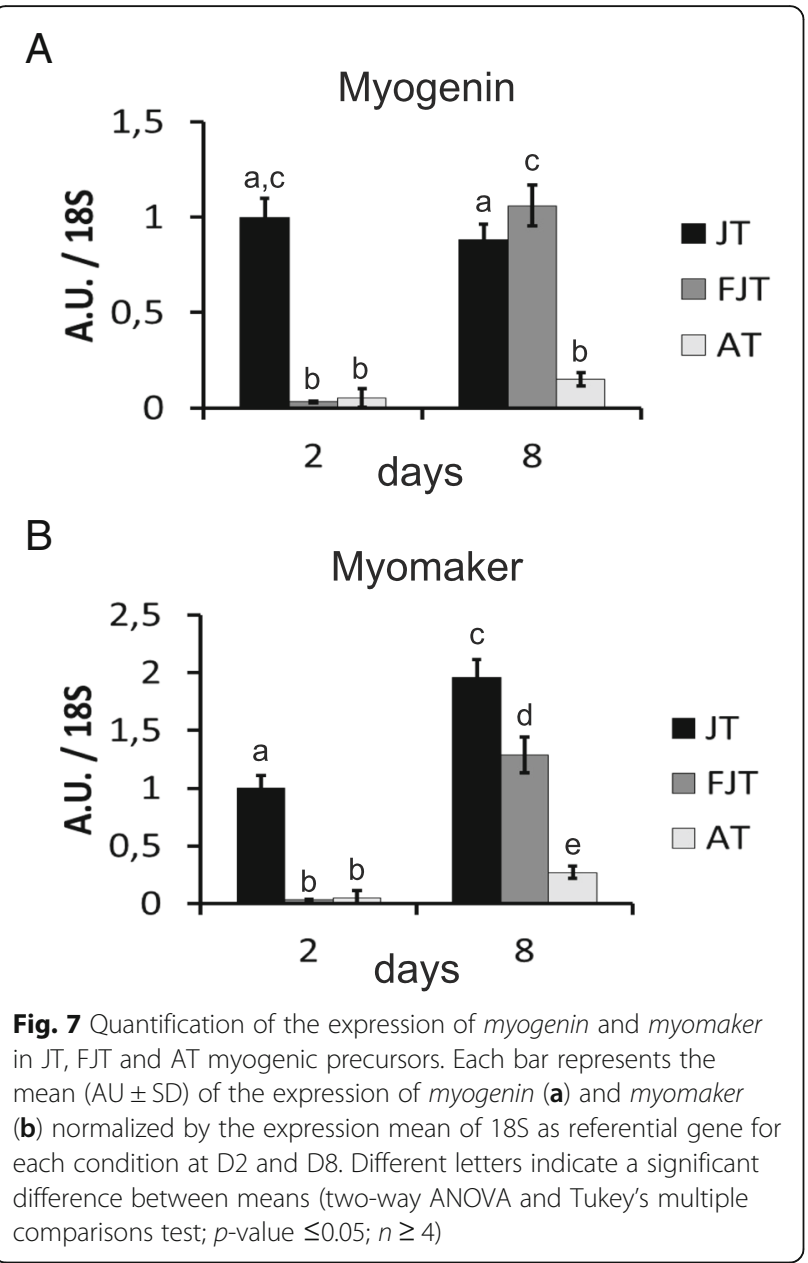

adhesion of satellite cells on laminin substrate to enrich them in culture [19, 34]. Although it has been reported that isolation procedures alter gene expression of myogenic precursors $[35,36]$, we assumed in this study that the differential ex vivo properties of trout satellite cells originating either from hyperplastic or non-hyperplastic muscle, somehow reflect intrinsic differences preexisting before their extraction from muscle.

First, we sought to identify and quantify proliferative satellite cells in muscle of growing versus non-growing trout using in vivo BrdU injection followed by double immuno-labeling of laminin and BrdU. In agreement with Alfei et al. (1989) [37], our results clearly evidenced a higher rate of BrdU positive cells in muscle of JT compared to FJT and AT, notably at sites corresponding to the satellite cell niche. This shows that fish hyperplastic muscle contains proliferative satellite cells well after hatching, what sharply contrasts with the mitotic quiescence of satellite cells located in mature mouse muscle [38].

Relative to satellite cells from non-hyperplastic muscle, satellite cells from juvenile trout were found to exhibit up-regulated gene set related to high metabolic activity as shown by enrichment in genes involved in translational efficiency and genes encoding structural and functional components of mitochondria, notably those involved in energy production for execution of biosynthesis events. Mitochondrial biogenesis has been associated with the shift from quiescence to proliferation of satellite cells $[39,40]$. In keeping with this, our result that matches meta-analyses of multiple transcriptomes revealing low expression of genes associated with oxidative phosphorylation in mouse quiescent satellite cells [41], supports the view that JT cells are intrinsically activated compared to satellite cells from non-hyperplastic muscle. Other major functional categories inferred from genes up-regulated in myogenic precursors derived from hyperplastic muscle were related to DNA replication and cell cycle. This finding, which is quite in agreement with the proliferation rate of these cells measured in vivo and ex vivo, strongly reinforces the view that satellite cells isolated from trout hyperplastic muscle are in an activated state. Also, several major genes signing myogenic differentiation were found to be overexpressed. Among them were myogenin which invalidation prevents myogenic differentiation in mouse [42] and myomaker which is necessary for myoblast fusion into myotube as shown by gene invalidation [15]. In keeping with this, it is interesting to note that mitochondrial activity, which is higher in JT satellite cells relative to FJT and AT cells, has been reported to positively regulate myogenesis [43]. Conversely, transcriptome of FJT and AT myogenic precursors, compared to that of JT myogenic precursors, revealed up regulation of genes involved in maintenance of stem cell quiescence, notably genes involved in Notch signaling [44] or known as marker of quiescent muscle stem cell. These results are in agreement with data obtained in mouse showing an up regulation of notch and Hey genes in quiescent satellite cells [45]. In addition, the up regulation of several genes involved in TGFbeta pathway was in line with a repression of differentiation of myogenic precursors [46]. Indeed, we notably observed an up-regulation of BMP receptor type 1 which knock-down in mouse satellite cells caused premature myogenic differentiation [47]. All these data support the view that satellite cells extracted from muscle of fasted trout or adult trout are close to a quiescent state compared to satellite cells from juvenile trout.

Another major result of our study was that behavior of satellite cells from hyperplastic muscle quite differs from that of satellite cells extracted from non-hyperplastic muscle. Specifically, we found that cultured JT myogenic precursors exhibited higher proliferation rate and differentiation capacities than FJT and AT myogenic precursors. These observations, that match transcriptome data, further support the view that myogenic cells from 
hyperplastic muscle of juvenile trout are intrinsically more potent to form myofibres than satellite cells from non-hyperplastic muscle. Also, we found that the low proliferation rate of myogenic cells observed in fasted trout muscle was maintained in vitro, suggesting an intrinsic inhibition of myogenic precursor proliferation. However, differentiation of FJT myogenic precursors was only delayed because qPCR and immunofluorescence analysis showed resumption of differentiation after 8 days of culture. In contrast, AT myogenic precursors exhibited a strong proliferation capacity in vitro suggesting that AT myogenic precursors were not delayed or close to senescent state that could explain their low myogenic capacities as observed in old mouse [48]. All together, these results showed differences in functional capacities of the two quiescent myogenic precursor's cells that could be interesting to investigate at molecular and cellular levels.

What could determine intrinsic myogenic capacity of JT cells? One possible cause, inferred from transcriptome analysis, could relate to epigenetic regulations of transcription. Indeed, up-regulation of genes involved in DNA methylation was found in JT myogenic precursors, notably several DNA methyl transferase (dnmt1, $3 \mathrm{ab}$ and $3 \mathrm{~b}$ ) known to be involved in muscle stem cell activation [49]. Furthermore, as previously reported in hyperplastic growth zone of trout larvae [50] and in activated satellite cells of mouse and trout regenerating muscle [51], we observed in JT cells the overexpression of many SWI/SNF chromatin remodeling enzymes, which dynamic recruitment regulate many stages of myogenesis [52].

\section{Conclusion}

The satellite cells from muscle of trout juveniles exhibit in vivo and ex vivo features of activation that are not found in satellite cells isolated from non-hyperplastic muscle. Thus, muscle hyperplastic growth in fish likely relates to the fact that satellite cells in these animals are intrinsically potent to form myofibres well after hatching.

\section{Methods \\ Animals}

Rainbow trout (Oncorhynchus mykiss) weighting from 2 g to $2 \mathrm{~kg}$ were reared to a $12 \mathrm{~h}$ light: $12 \mathrm{~h}$ dark photoperiod and $12 \pm 1{ }^{\circ} \mathrm{C}$ in a recirculating rearing system located in the Laboratory of Physiology and Genomics of Fish. Fish were fed daily ad libitum on a commercial diet or starved during 3 or 4 weeks. Fish were anesthetized with tricaine (MS-222, Sigma) at $50 \mathrm{mg} / \mathrm{L}$ or euthanized with tricaine at $200 \mathrm{mg} / \mathrm{ml}$.

\section{Measurement of satellite cell proliferation in situ}

Intra-peritoneal injections $(150 \mu \mathrm{g} / \mathrm{g}$ of body weight) of BrdU (Roche, no. 280879), dissolved in a solution composed with $\mathrm{NaOH}(0.02 \mathrm{~N})$ diluted with $\mathrm{NaCl} 0.9 \%$, were performed on juvenile rainbow trout (Oncorhynchus mykiss) (2 g, $n=5)$, 4 weeks fasted juvenile rainbow trout $(5 \mathrm{~g}, n=5)$ and $400-500 \mathrm{~g}$ rainbow trout $(n=6)$ which have been reported to exhibit low hyperplasia [4].

Muscle tissues were fixed in Carnoy fixative solution for $48 \mathrm{~h}$ at $4{ }^{\circ} \mathrm{C}$, progressively dehydrated and embedded in paraffin. Transverse paraffin sections $(10 \mu \mathrm{m}$ thick) were stained with laminin antibody (1:50, DSHB, D18-c) and BrdU labeling and detection kit (Roche Diagnostics, no. 11296736001) was used following the recommendations of manufacturer to measure the proliferation of the cells. Briefly, tissues were incubated for $30 \mathrm{~min}$ at $37^{\circ} \mathrm{C}$ with mouse IgG1 anti-BrdU (1:10, kit: 11296736001, Sigma) and, after $1 \mathrm{~h}$ incubation at room temperature in saturation buffer (BSA 1\%, 04-100-811C in PBST 0.1\%), tissues were incubated overnight at $4{ }^{\circ} \mathrm{C}$ with mouse IgG2a anti-laminin (1:1000, DSHB, D18-c). The secondary antibody were diluted (1:1000, Alexa 488 anti-IgG1 mouse A21121 to detect BrdU and Alexa 594 anti-IgG2a mouse A21135 to detect laminin) in PBST and applied for $1 \mathrm{~h}$ at room temperature. Tissues were then mounted in Mowiol containing $0.5 \mu \mathrm{g} / \mathrm{ml}$ of DAPI. Tissues cross sections were photographed using a Nikon digital camera coupled to a Nikon Eclipse 90i microscope. At least five images were taken per tissues and the number of nuclei BrdU positive localized between basal lamina and myofiber on the total number of nuclei under basal lamina (myo-nuclei) were calculated using cell counter plugin in Fiji software.

\section{Isolation of trout precursor myogenic cells}

For all studies, myogenic precursors were isolated from dorsal part of the white muscle of juvenile trout $(5 \mathrm{~g}$, JT), of 3-4 weeks fasted juvenile rainbow trout (5 g, FJT) and of adult rainbow trout $(1.5-2 \mathrm{~kg}, \mathrm{AT})$ as previously described [19]. The yield of cell extracted was lower in adult than in juvenile (JT: $1,6 \times 10^{6}$ cells/g of muscle; FJT: $1,4 \times 10^{6}$ cells/g of muscle; AT: $1,1 \times 10^{5}$ cells/g of muscle). Isolated myogenic precursors were plated on poly-L-lysine and laminin-coated plates at 80,000 cells per $\mathrm{cm}^{2}$ for every analysis except to proliferation measurement which were 60,000 cells per $\mathrm{cm}^{2}$.

\section{Gene expression analysis}

Using TRIzol reagent (Invitrogen, Carlsbad, CA, USA), total RNA were extracted from cells according to the manufacturer's recommendations. The total RNA (200 ng) were reverse transcribed into cDNA using the High Capacity cDNA Reverse Transcription kit, (Applied Biosystems) and random primers, according to the 
manufacturer's instructions. Target gene expression levels were determined by qPCR using specific primers (forward primer sequences; myogenin: AGCAGGAGAACGAC CAGGGAAC, myomaker: AATCACTGTCAAATGGTTA CAGA, and reverse primer sequences; myogenin: GTGT TGCTCCACTCTGGGCTG, myomaker: GTAGTCCCA CTCCTCGAAGT). Primers were design on two exons (myogenin) or in exon-exon boundaries (myomaker) to avoid genomic amplification. Quantitative PCR was performed on a StepOnePlus thermocycler (Applied Biosystems) using SYBR FAST qPCR Master Mix (PowerUp SYBR Green Master Mix kit, A25742, Applied Biosystems). Relative quantification of the target gene transcripts was made using $18 \mathrm{~S}$ gene expression as reference. Quantitative PCR was performed using $10 \mu \mathrm{l}$ of the diluted cDNA mixed with $300 \mathrm{nM}$ of each primer in a final volume of $20 \mu \mathrm{l}$. The PCR protocol was initiated at $95^{\circ} \mathrm{C}$ for $3 \mathrm{~min}$ for initial denaturation followed by the amplification steps $\left(20 \mathrm{~s}\right.$ at $95^{\circ} \mathrm{C}$ followed by $30 \mathrm{~s}$ at $60^{\circ} \mathrm{C}$ ) repeated 40 times. Melting curves were systematically monitored at the end of the last amplification cycle to confirm the specificity of the amplification reaction. The efficiency of the qPCR was about $80-100 \%$. Each PCR run included replicate samples (duplicate of PCR amplification) and negative controls (RNA-free samples, NTC). Data are presented as the ratio between the relative expression of the target gene and $18 \mathrm{~S}$.

\section{Microarray slides}

An Agilent-based microarray platform with $8 \times 60 \mathrm{~K}$ probes per slide was used (GEO platform record: GPL24910). Microarray data sets have been submitted to the GEO-NCBI with the accession number: GSE113758.

\section{RNA labeling and hybridization}

RNA samples $(N=5-6)$ from $24 \mathrm{H}$-cultured myogenic precursors from juvenile trout (JT), from 3 to 4 weeks fasted juvenile trout (FJT) and from adult trout (AT) were used for labelling and hybridization. For each sample, $150 \mathrm{ng}$ of RNA was Cy3-labelled according to the manufacturer's instructions (One-Color Microarray-Based Gene Expression Analysis (Low Input Quick Amp Labeling) Agilent protocol). Briefly, RNA was first reverse transcribed, using a polydT-T7 primer, Cy3 was incorporated by a T7 polymerase-mediated transcription and excess dye was washed using an RNeasy kit (Quiagen). The level of dye incorporation was evaluated using a spectrophotometer (Nanodrop ND1000, LabTech). 600 ng of labelled cRNA was then fragmented in the appropriate buffer (Agilent) for $30 \mathrm{~min}$ at $60^{\circ} \mathrm{C}$ before dilution $(v / v)$ in hybridization buffer. Hybridizations were performed in a microarray hybridization oven (Agilent) for $17 \mathrm{~h}$ at $65^{\circ} \mathrm{C}$, using two Agilent $8 \times 60 \mathrm{~K}$ high-density oligonucleotide microarray slides. Following hybridization, the slides were rinsed in gene expression wash buffers 1 and 2 (Agilent).

\section{Data acquisition and analysis}

Hybridized slides were scanned at a 3- $\mu \mathrm{m}$ resolution using the Agilent DNA microarray Scanner. Data were extracted using the standard procedures contained in the Agilent Feature Extraction (FE) software version 10.7.3.1. One AT sample that did not give good quality signal on microarray was discarded from the gene expression analysis. Arrays were normalized using GeneSpring software version 14.5. Using R software (3.2.2) a LIMMA (3.26.9) statistical test [24] (BH corrected p-val $<0.001$ ) was used to find differentially expressed genes between FJT and AT. Secondly, two LIMMA statistical tests $(\mathrm{BH}$ corrected $p$-val $<0.001$ ) were used to find differentially expressed genes between JT and FJT, and between JT and AT. We kept significant differentially expressed genes with an expression mean in at least one condition above or equal to 6 , corresponding at 3 times background (normalized values). Thirdly, we kept commons genes found in this two differential analysis in the same regulation way with JT as referential condition. For clustering analysis, log transformed values were median-centered and an average linkage clustering was carried out using CLUSTER 3.0 software and the results were visualized with TreeView software (https:// sourceforge.net/projects/jtreeview/files/). GO enrichment analysis was performed using Database for Annotation, Visualization and Integrated Discovery (DAVID 6.7) software tools.

\section{Analysis of cell proliferation}

Cells were cultured in presence of $10 \mu \mathrm{M}$ BrdU during $24 \mathrm{H}$ before sampling and cells were collected at days 2 , 5, 8 and 11. The cells were fixed with ethanol/glycine buffer (100\% ethanol, $50 \mathrm{mM}$ glycine, $\mathrm{pH} 2)$. A BrdU labeling and detection kit $(11,296,736,001$, Sigma) was used following the recommendations of manufacturer to measure the proliferation of the cells. Briefly, the cells were incubated for $30 \mathrm{~min}$ at $37^{\circ} \mathrm{C}$ with mouse anti-BrdU, washed, and then incubated with the secondary antibody anti-mouse FITC for $30 \mathrm{~min}$. Cells were then mounted in Mowiol containing $0.5 \mu \mathrm{g} / \mathrm{ml}$ DAPI. Cells were photographed using a Nikon digital camera coupled to a Nikon Eclipse 90i microscope. Seven images were taken per well and the number of BrdU positive nuclei on the total number of nuclei was automatically calculated using a macro command on Visilog (6.7) software.

\section{Analysis of cell differentiation}

On days 2, 5, 8 and 11 of culture, cells on glass coverslips were briefly washed twice with phosphate-buffered saline (PBS) and fixed for $30 \mathrm{~min}$ with $4 \%$ paraformaldehyde in PBS. After three washes, cells were saturated for 
$1 \mathrm{~h}$ with 3\% BSA, 0.1\% Tween-20 in PBS (PBST). Cells were incubated at room temperature for $3 \mathrm{~h}$ with the primary antibody anti-myosin heavy chain (MyHC, DSHB, MF20-c, 1:50) in blocking buffer [19]. The secondary antibodies were diluted (1:1000, Alexa 488 A11001) in PBST and applied for $1 \mathrm{~h}$ at room temperature. Cells were mounted with Mowiol containing DAPI $(0.5 \mu \mathrm{g} / \mathrm{ml})$. Cells were photographed using a Nikon digital camera coupled to a Nikon Eclipse 90i microscope. Five images were taken per well and the number of nuclei contained in MyHC positive cells on the total number of nuclei was automatically calculated using a macro command on Visilog (6.7) software.

\section{Statistical analysis}

A two-way ANOVA analysis (time and conditions as factors) with a Tukey's post hoc multiple comparisons test was performed on qPCR data, proliferation ratio and differentiation ratio. A Kruskal-Wallis test with a Dunn's post hoc multiple comparisons test was performed on in situ satellite cells proliferation data. A $p$-value below 0.05 was considered significant. All the statistical analyses were performed with the $\mathrm{R}$ packages (3.5.1 version).

\section{Abbreviations}

AT: Adult trout; BrdU: 5-bromo-2'-deoxy-uridine; DEGs: Differentially expressed genes; FJT: Fasting Juvenile Trout; JT: Juvenile Trout

\section{Acknowledgements}

We also thank C. Duret for husbandry of injected trout

\section{Funding}

These researches were funded by National Institute of Agronomic Research (INRA). The fellowship of Sabrina Jagot was supported by INRA PHASE and the Région Bretagne. The funders did not intervene in the design, analysis and interpretation of the data.

\section{Availability of data and materials}

Gene expression data supporting the results of this article are available in the Gene Expression Omnibus (GEO) repository under the accession number: GSE113758.

\section{Authors' contributions}

JCG conceived and supervised the study. SJ, AL and NS performed the experiments. SJ, PYR and JCG analyzed the data. JB developed a program for cell proliferation and differentiation quantification. SJ, PYR and JCG wrote the paper and AL, NS and JB made a critical reading of the manuscript. All authors read and approved the final manuscript.

\section{Ethics approval}

Fish used in this study were reared and handled in strict accordance with French and European policies and guidelines of the Institutional Animal Care and Use Committee (no. 3312-20 15,121,511 022362 and 3313-20 15,121,511 094929), which approved this study.

\section{Consent for publication}

Not applicable.

\section{Competing interests}

The authors declare that they have no competing interests.

\section{Publisher's Note}

Springer Nature remains neutral with regard to jurisdictional claims in published maps and institutional affiliations.

Received: 18 May 2018 Accepted: 14 November 2018

Published online: 03 December 2018

\section{References}

1. Rowlerson A, Mascarello F, Radaelli G, Veggetti A. Differentiation and growth of muscle in the fish Sparus aurata (L): II. Hyperplastic and hypertrophic growth of lateral muscle from hatching to adult. J Muscle Res Cell Motil. 1995;16:223-36.

2. Koumans JTM, Akster HA, Booms GHR, Osse JWM. Growth of carp (Cyprinus carpio) white axial muscle; hyperplasia and hypertrophy in relation to the myonucleus/sarcoplasm ratio and the occurrence of different subclasses of myogenic cells. J Fish Biol. 1993;43:69-80.

3. Veggetti A, Mascarello F, Scapolo PA, Rowlerson A. Hyperplastic and hypertrophic growth of lateral muscle in Dicentrarchus labrax (L.). Anat Embryol. 1990;182:1-10.

4. Stickland NC. Growth and development of muscle fibres in the rainbow trout (Salmo gairdneri). J Anat. 1983;137(Pt 2):323-33.

5. Rescan P-Y, Rallière $C$, Lebret $V$, Fretaud $M$. Analysis of muscle fibre input dynamics using a myog:GFP transgenic trout model. J Exp Biol. 2015;218: 1137-42.

6. Johnston IA, Lee H-T, Macqueen DJ, Paranthaman K, Kawashima C, Anwar A, et al. Embryonic temperature affects muscle fibre recruitment in adult zebrafish: genome-wide changes in gene and microRNA expression associated with the transition from hyperplastic to hypertrophic growth phenotypes. J Exp Biol. 2009;212:1781

7. Rowlerson A, Veggetti A. Cellular mechanisms of post-embryonic muscle growth in aquaculture species. In: Muscle development and growth Academic Press; 2001. p. 103-40

8. Gabillard J-C, Kamangar BB, Montserrat N. Coordinated regulation of the $\mathrm{GH} / \mathrm{IGF}$ system genes during refeeding in rainbow trout (Oncorhynchus mykiss). J Endocrinol. 2006;191:15-24.

9. Fauconneau B, Paboeuf G. Effect of fasting and refeeding on in vitro muscle cell proliferation in rainbow trout (Oncorhynchus mykiss). Cell Tissue Res. 2000;301:459-63.

10. Mauro A. SATELLITE CELL OF SKELETAL MUSCLE FIBERS. J Biophys Biochem Cytol. 1961;9:493-5.

11. Miller JB, Schaefer L, Dominov JA. 6 seeking muscle stem cells. In: Pedersen RA, Schatten GP, editors. Current topics in developmental biology: Academic Press; 1998. p. 191-219. http://www.sciencedirect.com/science/ article/pii/S0070215308603828

12. Dumont NA, Wang YX. Intrinsic and extrinsic mechanisms regulating satellite cell function. Development. 2015:142:1572-81.

13. Yablonka-Reuveni Z, Rivera AJ. Temporal expression of regulatory and structural muscle proteins during Myogenesis of satellite cells on isolated adult rat fibers. Dev Biol. 1994;164:588-603.

14. Zammit PS, Partridge TA, Yablonka-Reuveni Z. The skeletal muscle satellite cell: the stem cell that came in from the cold. J Histochem Cytochem. 2006; 54:1177-91.

15. Millay DP, O'Rourke JR, Sutherland LB, Bezprozvannaya S, Shelton JM, BasselDuby $R$, et al. Myomaker is a membrane activator of myoblast fusion and muscle formation. Nature. 2013;499:301.

16. Koumans JTM, Akster HA. Myogenic cells in development and growth of fish. Comp Biochem Physiol A Physiol. 1995;110:3-20.

17. Gurevich DB, Nguyen PD, Siegel AL, Ehrlich OV, Sonntag C, Phan JMN, et al. Asymmetric division of clonal muscle stem cells coordinates muscle regeneration in vivo. Science. 2016;353. https://doi.org/10.1126/science. aad9969.

18. Koumans JTM, Akster HA, Booms RGH, Osse JWM. Influence of fish size on proliferation and differentiation of cultured myosatellite cells of white axial muscle of carp (Cyprinus carpio L.). Differentiation. 1993;53:1-6.

19. Gabillard J, Sabin N, Paboeuf G. In vitro characterization of proliferation and differentiation of trout satellite cells. Cell Tissue Res. 2010;342:471-7.

20. Duran BO d S, Fernandez GJ, Mareco EA, Moraes LN, Salomão RAS, Gutierrez de Paula T, et al. Differential microRNA expression in Fast- and slow-twitch skeletal muscle of Piaractus mesopotamicus during growth. PLoS One. 2015; 10:e0141967. 
21. Wang $T$, Wang $X$, Zhou $H$, Jiang $H$, Mai $K$, He G. The mitotic and metabolic effects of phosphatidic acid in the primary muscle cells of turbot (Scophthalmus maximus). Front Endocrinol. 2018;9:221.

22. Bower NI, Taylor RG, Johnston IA. Phasing of muscle gene expression with fasting-induced recovery growth in Atlantic salmon. Front Zool. 2009;6:1-13.

23. Montserrat N, Gabillard JC, Capilla E, Navarro MI, Gutierrez J. Role of insulin, insulin-like growth factors, and muscle regulatory factors in the compensatory growth of the trout (Oncorhynchus mykiss). Gen Comp Endocrinol. 2007;150. https://doi.org/10.1016/j.ygcen.2006.11.009.

24. Smyth GK. Linear models and empirical Bayes methods for assessing differential expression in microarray experiments. Stat Appl Genet Mol Biol. 2004;3(1). Article 3.

25. Hong P, Chen K, Huang B, Liu M, Cui M, Rozenberg I, et al. HEXIM1 controls satellite cell expansion after injury to regulate skeletal muscle regeneration. J Clin Invest. 2012;122:3873-87.

26. Zhu $H$, Xiao F, Wang $G$, Wei $X$, Jiang $L$, Chen $Y$, et al. STAT3 regulates selfrenewal of adult muscle satellite cells during injury-induced muscle regeneration. Cell Rep. 2016;16:2102-15.

27. Pallafacchina G, François S, Regnault B, Czarny B, Dive V, Cumano A, et al. An adult tissue-specific stem cell in its niche: a gene profiling analysis of in vivo quiescent and activated muscle satellite cells. Stem Cell Res. 2010:4:77-91.

28. Alter J, Bengal E. Stress-induced C/EBP homology protein (CHOP) represses MyoD transcription to delay myoblast differentiation. PLoS One. 2011;6:e29498.

29. Mohassel P, Rosen P, Casciola-Rosen L, Pak K, Mammen AL. Expression of the dermatomyositis autoantigen TIF1 $\gamma$ in regenerating muscle. Arthritis \& Rheumatology (Hoboken, NJ). 2015;67:266-72.

30. Wang C, Liu W, Liu Z, Chen L, Liu X, Kuang S. Hypoxia inhibits myogenic differentiation through $\mathrm{p} 53$ protein-dependent induction of Bhlhe40 protein. J Biol Chem. 2015;290:29707-16.

31. Wang L, Jia Y, Rogers $H$, Wu Y-P, Huang S, Noguchi CT. GATA-binding protein 4 (GATA-4) and T-cell acute leukemia 1 (TAL1) regulate myogenic differentiation and erythropoietin response via cross-talk with Sirtuin1 (Sirt1). J Biol Chem. 2012;287:30157-69.

32. Day K, Shefer G, Richardson JB, Enikolopov G, Yablonka-Reuveni Z. NestinGFP reporter expression defines the quiescent state of skeletal muscle satellite cells. Dev Biol. 2007;304:246-59.

33. Gayraud-Morel B, Pala F, Sakai H. Isolation of muscle stem cells from mouse skeletal muscle. Methods Mol Biol Clifton NJ. 2017;1556. https://doi.org/10. 1007/978-1-4939-6771-1_2.

34. Foster RF, Thompson JM, Kaufman SJ. A laminin substrate promotes myogenesis in rat skeletal muscle cultures: analysis of replication and development using antidesmin and anti-BrdUrd monoclonal antibodies. Dev Biol. 1987;122:11-20.

35. Machado L. Esteves de Lima J, Fabre O. in situ fixation redefines quiescence and early activation of skeletal muscle stem cells. Cell Stem Cell. 2017;21.

36. Van den Brink SC, Sage F. Single-cell sequencing reveals dissociationinduced gene expression in tissue subpopulations. Nat Methods. 2017;14. https://doi.org/10.1038/nmeth.4437.

37. Alfei L, Maggi F, Parvopassu F, Bertoncello G, Vita R. Postlarval muscle growth in fish: a DNA flow cytometric and morphometric analysis; 1989.

38. Schultz E, Gibson MC, Champion T. Satellite cells are mitotically quiescent in mature mouse muscle: an EM and radioautographic study. J Exp Zool. 1978; 206:451-6.

39. Rocheteau P, Gayraud-Morel B, Siegl-Cachedenier I, Blasco MA, Tajbakhsh S. A subpopulation of adult skeletal muscle stem cells retains all template DNA strands after cell division. Cell. 2012;148:112-25.

40. Rodgers JT, King KY, Brett JO, Cromie MJ, Charville GW, Maguire KK, et al. mTORC1 controls the adaptive transition of quiescent stem cells from G0 to GAlert. Nature. 2014;510:393-6.

41. Pietrosemoli N, Mella S, Yennek S, Baghdadi MB, Sakai H, Sambasivan R, et al. Comparison of multiple transcriptomes exposes unified and divergent features of quiescent and activated skeletal muscle stem cells. Skelet Muscle. 2017;7:28

42. Hasty P, Bradley A, Morris JH, Edmondson DG, Venuti JM, Olson EN, et al. Muscle deficiency and neonatal death in mice with a targeted mutation in the myogenin gene. Nature. 1993;364:501

43. Wagatsuma A, Sakuma K. Mitochondria as a potential regulator of Myogenesis. Sci World J. 2013;2013:593267.
44. Mourikis P, Sambasivan R, Castel D, Rocheteau P, Bizzarro V, Tajbakhsh S. A critical requirement for notch signaling in maintenance of the quiescent skeletal muscle stem cell state. Stem Cells. 2012;30:243-52.

45. Fukada S, Uezumi A, Ikemoto M, Masuda S, Segawa M, Tanimura N, et al. Molecular signature of quiescent satellite cells in adult skeletal muscle. Stem Cells. 2007;25:2448-59.

46. Liu D, Black BL, Derynck R. TGF- $\beta$ inhibits muscle differentiation through functional repression of myogenic transcription factors by Smad3. Genes Dev. 2001;15:2950-66.

47. Ono Y, Calhabeu F, Morgan JE, Katagiri T, Amthor H, Zammit PS. BMP signalling permits population expansion by preventing premature myogenic differentiation in muscle satellite cells. Cell Death Differ. 2011;18:222-34.

48. Chargé SBP, Brack AS, Hughes SM. Aging-related satellite cell differentiation defect occurs prematurely after ski-induced muscle hypertrophy. Am J Phys Cell Phys. 2002;283:C1228-41.

49. Laker RC, Ryall JG. DNA methylation in skeletal muscle stem cell specification, proliferation, and differentiation. Stem Cells Int. 2016;2016:5725927.

50. Rescan P-Y, Montfort J, Fautrel A, Ralliere C, Lebret V. Gene expression profiling of the hyperplastic growth zones of the late trout embryo myotome using laser capture microdissection and microarray analysis. BMC Genomics. 2013;14:173.

51. Montfort J, Le Cam A, Gabillard J-C, Rescan P-Y. Gene expression profiling of trout regenerating muscle reveals common transcriptional signatures with hyperplastic growth zones of the post-embryonic myotome. BMC Genomics. 2016;17:810.

52. Toto PC, Puri PL, Albini SSWI. SNF-directed stem cell lineage specification: dynamic composition regulates specific stages of skeletal myogenesis. Cell Mol Life Sci. 2016;73:3887-96.
Ready to submit your research? Choose BMC and benefit from:

- fast, convenient online submission

- thorough peer review by experienced researchers in your field

- rapid publication on acceptance

- support for research data, including large and complex data types

- gold Open Access which fosters wider collaboration and increased citations

- maximum visibility for your research: over $100 \mathrm{M}$ website views per year

At BMC, research is always in progress.

Learn more biomedcentral.com/submissions 